\title{
Os sentidos de riscos atribuidos à alimentação entre cuidadores domésticos
}

I ${ }^{1}$ Micheli Dantas Soares, ${ }^{2}$ Leny Alves Bomfim Trad I

Resumo: Este trabalho tem por objetivo compreender os sentidos atribuídos aos discursos veiculados no campo social sobre alimentação e nutrição por cuidadores domiciliares de crianças. Foi realizado um estudo de cunho etnográfico num contexto urbano da cidade de Salvador/BA, representado por grupos domésticos do segmento de camadas baixas urbanas, durante o ano de 2010. Foram realizadas observações e entrevistas semiestruturadas com cuidadores, as quais foram analisadas com base na fenomenologia hermenêutica. Os resultados permitem afirmar que os sentidos sobre alimentação e nutrição estão margeados por significados de riscos, a partir de conteúdos de natureza técnico-científica. A imagem tecnológica dos alimentos está fortemente presente nos modos de pensar a comida cotidiana. Contudo, não apresenta um quadro de estabilidade, podendo variar dentro do mesmo grupo social, considerando a referência na qual se assenta tal significação.

> Palavras-chave: assunção de riscos; alimentação; práticas alimentares.

\author{
1 Nutricionista. Doutora em \\ Saúde Coletiva pelo Instituto de \\ Saúde Coletiva da Universidade \\ Federal da Bahia; professora do \\ Centro de Ciências da Saúde \\ da Universidade Federal do \\ Recôncavo da Bahia, Brasil. \\ Endereço eletrônico: michelid@ \\ ufrb.edu.br \\ 2 Psicóloga; doutora em \\ Ciências Sociais e Saúde pela \\ Universidad de Barcelona; pós- \\ doutora em Antropologia da \\ Saúde pela Universitat Lumière \\ Lyon 2; professora associada IV \\ do Instituto de Saúde Coletiva, \\ Universidade Federal da Bahia, \\ Brasil. Endereço eletrônico: \\ lenytrad@yahoo.com.br
}




\section{Introdução}

$\mathrm{Na}$ atualidade, acentua-se a complexidade das práticas alimentares em função das mudanças que alteram, sobremaneira, as regras e os conteúdos que outrora as organizavam (FISCHLER, 1995; POULAIN, 2004). Essas mudanças são caudatárias de amplos processos que marcam a alta modernidade; dentre estes, a destradicionalização dos modos de gestão da vida, por meio da qual, a assunção do risco, expresso no seu enfrentamento e convívio diários, diferencia os modos de organização da sociedade atual. Operando na base de constituição da sociedade, os dispositivos discursivos sobre riscos, produzidos pelos sistemas peritos - experts -, penetram no cotidiano e reclamam dos sujeitos processos reflexivos face à sua presença hegemônica, instruindo-os à "colonização do futuro", em conformidade com suas estimativas (GIDDENS, 2002).

Ecoam no campo da saúde e da alimentação e nutrição os reflexos dessas mudanças, evidenciados pelo lugar que a cultura da saúde/saudável ostenta nos tempos atuais (SFEZ, 1993), razão pela qual germinam discursos e práticas cujo fundamento é o status do controle do risco.

A discussão do risco no campo da saúde tem sido profícua. Sem pretensão de aportar todas as suas variantes, sublinhamos algumas perspectivas que importam ao interesse deste estudo. A primeira coloca em evidencia o reconhecimento do alcance de sua "plena cidadania científica" no campo da saúde, organizando a linguagem e o método epidemiológico, conferindo-lhe, ele próprio, a "identidade discursiva" dos epidemiologistas (AYRES, 2011). A segunda perspectiva diz respeito às armadilhas associadas ao uso da categoria "risco", destacando-se aqui os limites dos métodos estimativos que, por seu próprio viés, reduzem a complexidade do real, transmutando-se em recomendações e diretrizes mais ou menos simplificadas e, aparentemente, destituídas de valores e interesses (CZERESNIA, 2003). A terceira, por derivação, denuncia os desdobramentos políticos e éticos do seu uso nos modos de regulação da vida, quando os meios de comunicação participam das estruturas discursivas sobre o enfrentamento de riscos, subscritos pelo campo científico (BAGRICHEVSKY et al., 2010; VAZ et al., 2007; RANGEL, 2007), em função do paroxismo que logrou, outrora impensável (CASTIEL; GUILAN; FERREIRA, 2010).

Assim, como produto do seu tempo, o campo da saúde é orbitado pelo conceito de risco, cujo uso tem-se destinado a cercar o cotidiano dos sujeitos 
de um conjunto de práticas que vislumbram sedimentar modos de vida saudáveis. No campo da saúde, opera-se uma relação na qual o saudável abriga, necessariamente, oposição ou atenuação de riscos (LUZ, 2003). Imbricado ao campo da saúde, o da alimentação e nutrição se constitui e se estrutura herdando esse mesmo padrão de relação.

Considerando a relação intrínseca entre a alimentação e a saúde, entre o saudável e os riscos que o afetam, presenciam-se múltiplas referências discursivas e agentes que promovem a circulação de informações no que tange à alimentação e nutrição, cujos conteúdos herdam os avanços no campo científico. Assim, considerando que a dietética contemporânea se apresenta mais difundida e molecularizada, não se fala mais de doenças e problemas de saúde, mas de elementos cada vez mais atomizados do campo do conhecimento específico. Ou seja, estamos afunilando e endogenando nosso olhar sobre o corpo e os alimentos; para além da obesidade, também o colesterol, e na distinção do bom e do mau colesterol (ORY, 2008; SANTOS, 2008). Destarte, o sistema classificatório dos alimentos não aponta mais o que é comestível ou não, mas o que é bom para a saúde ou não, gorduras saturadas ou insaturadas, ácidos graxos ômega 3 ou 6 (AZEVEDO, 2008).

Para Santana (2003), há, de um modo geral, um interesse crescente de se compreender a linguagem médico-nutricional sobre os alimentos, a qual passa a integrar o vocabulário corrente da população. Para essa autora, ocorre uma espetacularização fotogênica da comida na modernidade, fundada numa sociedade imagética, na qual a "intensa fotogenia do prato cria seu 'outro", e na qual os elementos químicos dos alimentos são protagonistas dessa cena espetacular. Por seu turno, as peças publicitárias recorrem à composição química dos alimentos e dos produtos para proclamarem o controle do risco, utilizando-se de estratégias que criam uma imagem onírica da alimentação saudável (VILLAGELIM et al., 2012).

Sobre esse cenário, Fischler (1995) entende que as prescrições alimentares não são mais individuais e, sim, de massa. Ganharam audiência pública, orquestradas, sobretudo, pelo Estado, sendo tanto mais profiláticas, quanto terapêuticas. Por sua vez, Arnaiz (1996) advoga que a massificação de informações alimentares é uma característica das sociedades industrializadas, resultante do franco crescimento de fontes de informação - tanto escritas quanto audiovisuais - que se iniciou na segunda metade do século XX. Tal característica leva a autora a assumir que estamos vivendo numa "sociedade hiperinformada" em nível alimentar. 
Discutindo o contexto no qual esse fenômeno se desenvolve, Arnaiz destaca que, aliado ao crescimento das fontes informativas, os valores vigentes na atualidade - estéticos, médico-nutricionais e gastronômicos - guardam relação com a alimentação, razão pela qual diversos setores da sociedade se interessaram pelo tema alimentar. A autora prossegue afirmando que a alimentação foi deslocada do espaço privado para o público, no qual se apresenta revestida de múltiplas "epígrafes", na dependência dos interesses dos setores que a utilizam, tais como cultura, saúde, economia, estética, etc.

Em suma, as orientações nutricionais estão cada vez mais disseminadas e, também, contraditórias. Estudos e pesquisas sobre os efeitos benéficos e maléficos dos alimentos são objetos muito frequentes dos periódicos científicos e são notícias correntes na mídia, sendo anunciadas pelos próprios cientistas que passaram a ocupar lugar mais ou menos cativo nesses espaços (LUPTON, 1995; AZEVEDO, 2008; VAZ, 2007).

As noções de risco, por sua vez, apresentam-se multiversas, o que significa dizer que talvez os riscos não sejam universais e generalizáveis (ARNAIZ, 1996). Para além dos riscos associados aos alimentos, somam-se aqueles derivados da multiplicidade e diversidade de informaçóes e as contradiçôes que nelas se apresentam (ARNAIZ, 1996; LUPTON, 1995; FICHELER, 1995). Pode-se, assim, considerar que as noções de risco são porosas e se espalham no espaço social, de modo que são frequentemente apropriadas pelos leigos, refletindose no cotidiano, haja vista que todo espaço social não escapa à inundação das informações advindas dos sistemas peritos, as quais provocam revisões e reinterpretações cotidianas para o ajustamento desses conhecimentos às noçôes das estimativas de riscos por eles produzidas.

A partir do cenário descrito, este estudo teve por objetivo analisar as percepções de cuidadores domésticos de crianças sobre risco associado à alimentação, de modo a contribuir para a discussão em torno dos reflexos que as noções de risco imprimem no campo social da alimentação. Trata-se de um recorte de um estudo maior que pretendeu compreender os sentidos atribuídos aos discursos sobre alimentação e nutrição, cuja análise indicou a preponderância da noção de risco nos discursos sobre alimentação enunciados pelo grupo estudado. 
Esta investigação é um recorte de uma pesquisa mais ampla, que apresenta dois matizes inter-relacionados: a experiência do cuidado alimentar praticado no grupo doméstico e os sentidos atribuídos pelos cuidadores domésticos aos discursos sobre alimentação e nutrição no mundo contemporâneo. Neste artigo, enfocam-se as percepções sobre risco associado à alimentação por cuidadores domésticos de crianças.

Trata-se de um estudo qualitativo realizado num contexto urbano da cidade de Salvador/Bahia, num bairro localizado na Orla Atlântica, considerado periférico do ponto de vista social por abrigar uma população de baixa e média renda. Foram realizadas observações e entrevistas em profundidade com os cuidadores, as quais foram gravadas, transcritas e interpretadas com base na fenomenologia hermenêutica.

O universo pesquisado foi composto por seis grupos domésticos extensos, que abrigavam de três a quatro famílias cada, totalizando 21 atores sociais entrevistados. Todos os agentes cuidadores entrevistados eram do sexo feminino, com idade variando entre 23 e 65 anos. Embora as cenas cotidianas a partir das quais o estudo foi realizado contassem também com a presença de homens, as narrativas sobre a alimentação foram predominantemente anunciadas por mulheres.

Frequentou-se cada um dos grupos domésticos ao menos uma vez por semana, durante oito meses de trabalho de campo no ano de 2010. Em cada um dos grupos domésticos estudados foi experimentada uma média de dez a quinze encontros ao longo dos meses de campo. Em cada encontro permanecia-se em contato com o grupo por um período de duas a três horas, variável conforme o desenvolver da conversa e da cena.

As entrevistas acolheram os sentidos da alimentação cotidiana e do modo como os agentes representavam os discursos veiculados sobre alimentação. A análise empreendida na pesquisa tomou como substrato tanto as narrativas produzidas nos diálogos com os membros do grupo doméstico quanto as observações e impressões sensíveis registradas no diário de campo, apreendendo os núcleos significativos, em referência com um sistema maior de significação, 
tanto do ponto de vista da temporalidade - o passado e a tradição - quanto situacional - o grupo doméstico, o bairro, o espaço social. Nesse sentido, o risco associado à alimentação foi a categoria êmica mais predominantemente evocada pelas agentes.

O projeto foi aprovado pelo Comitê de Ética do Instituto de Saúde Coletiva da Universidade Federal da Bahia (ISC/UFBA), sob registro 016-09/CEP-ISC em maio de 2009, tendo cumprido todas as normas da Resolução no. 196/96, vigente à época.

\section{Resultados e discussão}

\section{Entre a tradição e modernidade na esteira da indústria}

Algumas narrativas apreendidas sinalizam para a presença do conhecimento científico ressignificando as experiências do cuidar no cotidiano, que, por sua vez, extrapola o cuidado alimentar, presentificando-se em todas as dimensões do cuidar.

Na minha infância, minha mãe me dava tudo. Não mata, não. Hoje a gente não faz mais isso, tem coisa mais avançada. Antigamente, tinha uma diarreia, não sabia o que era infecção, e dava um chá e levava dias com aquilo, pensava que era normal. Hoje a gente sabe que tem infecção e sabe que não pode dar coisa pesada, dar gordura. Porque hoje o conhecimento já tá mais espalhado, tem mais informação. (D. Sonia)

D. Sonia oferece-nos duas expressóes que fazem referência à temporalidade, em tempos de destradicionalização, tal como discutido por Giddens (2002). Ao se referir ao tempo de sua mãe para a resolução de problemas de saúde, acionando o uso de chás, recurso tão recorrente em tempos idos, faz uma clara distinção de natureza terminológica entre uma diarreia persistente do passado e uma infecção em tempos colonizados pelo conhecimento científico (GIDDENS, 2002). O significado que se atribui às experiências de adoecimento são também produtos de seu tempo, guardam cumplicidade com valores sociais e culturais presentes nesse tempo, no qual o conhecimento científico parece compor, de modo mais contundente que outrora, esse arsenal de valores através dos quais os sujeitos dão sentidos às suas experiências.

Faz-se necessário abrir um parêntese com referência à utilização de chás. Não se quer dizer que o seu uso seja menos habitual que em tempos de gerações anteriores. Foi possível observar que se lança mão desse alimento também com regular frequência. Todavia, quem comumente guarda o conhecimento sobre 
suas propriedades e seus fins terapêuticos são as agentes de gerações mais antigas.

Nesse sentido, é possível perceber que são elas as pessoas acionadas quando há problemas de saúde. Conforme Menéndez (1992), são as mulheres as primeiras agentes de saúde e o espaço doméstico a primeira esfera de atenção à saúde, ainda que se acione com mais frequência o sistema formal:

Hoje em dia a medicina tá avançada, mas de primeira a médica da minha casa era eu mesma... Aqui, as meninas me perguntam que está sentindo uma coisa ou outra, o que faz. (D. Maria)

Apoiamo-nos também em Giddens (2007) para afirmar que, no domínio familiar, dentre outras esferas da vida, práticas tradicionais permanecem mais resistentes que em outras partes, fornecendo uma espécie de estrutura para ação no cotidiano. Todavia, tal como este autor também defende, toda tradição se orienta pela repetição, e, em alguma medida, a preservação de seus ritos e conteúdos de verdade permanece no domínio de um dado guardiāo. Nesse caso, as agentes de gerações precedentes são requeridas para trazer à tona o dado conhecimento.

Num diálogo entre duas gerações da mesma família, é possível perceber o embate de posicionamentos sobre a alimentação do presente e do passado, espelhando muitas das expressões que marcam a modernidade tardia. Trata-se de um diálogo entre uma mãe, D. Laura, de 55 anos, e Angélica, sua filha, de 24 anos. Diz D. Laura:

A alimentação mudou no tempo. Por exemplo, antigamente quando eu fui criada na minha casa não tinha uma geladeira; hoje em dia as coisas já são geladas. A verdura, o coentro, você plantava para comer. Hoje não, você compra que vem não sei de onde, já vem com não sei quanto de remédio, já nasceu com remédio, já vem de uma estufa, pra chegar até a gente já passou por não sei quantos processos. A carne, da mesma forma. Antigamente, aqui mesmo onde a gente morava, matava o porco e pegava na hora, ou então ia para São Joaquim e comprava carne fresca. Eu tenho saudade, não gosto dessa tecnologia que se formou. Antes tinha mais saúde, era mais nutritiva, hoje em dia tem Danoninho, e antes todo muito vivia mais; hoje em dia tem colesterol alto, diabetes, é a mudança da alimentação. Minha mãe mesmo tem 79 anos e não tem nada. Hoje a alimentação é tudo tecnológica.

Angélica se contrapõe à mãe, dizendo:

Antes, não tinha variedade, tinha que acordar de madrugada para pegar o peixe, hoje tem várias coisas na geladeira, tem uma galinha na geladeira, tem uma calabresa, uma carne de sertão.

O diálogo continua, com D. Laura:

Vocês acham que é mais difícil porque nasceram nesse tempo de hoje. 
A filha, por sua vez, assevera:

Minha mãe, as crianças nem brincavam, porque tinham que ajudar os pais. As crianças tinham que trabalhar.

D. Laura responde:

Eu tive infância, sim. Brincava de roda, de melancia, de amarelinha, de tudo que é brincadeira de criança mesmo, não é essa coisa tecnológica de hoje, de videogame, de computador.

E por fim, Angélica completa:

Hoje é tudo igual, se resume tudo igual. Ela tem essa opinião porque ela vem de antes, não tem possibilidade de voltar como era antes, hoje fica com tudo na mesma opção. É falta de opção mesmo, não tem possibilidade de fazer como era antes, porque não tem mais dificuldade de antes. Por exemplo, a galinha matava, tinha que fazer na lenha, hoje você pode assar, fritar, cozinhar. O peixe já vem tratado, então antigamente tinha mais trabalho.

Entram em cena diferentes noções de risco, um diálogo que expressa também um dos desdobramentos da industrialização discutidos por Poulain (2004), resultando na separação crescente entre o alimento e a natureza. D. Laura faz referência à alimentação de hoje, apresentando-a como contraponto à do seu tempo, entendida como mais saudável e nutritiva. $\mathrm{O}$ principal elemento a configurar uma alimentação menos saudável, na sua perspectiva, é a tecnologia, que agrega riscos em todo percurso do sistema alimentar, pois que mais distante da natureza. No passado, a dificuldade de se adquirir o alimento contrapóe-se, desfavoravelmente, à variedade de opções que se apresentam hoje no mercado, na perspectiva de Angélica. O risco que D. Laura evoca no seu enunciado refere-se aos tempos da modernidade tardia, um risco que não parece reconhecer como sendo do seu tempo; um risco fabricado na perspectiva de Giddens (2007), produto do impacto do conhecimento gerado sobre o mundo. Diferente do risco que Angélica sinaliza como do tempo de sua mãe, o da escassez, da não provisão, da dificuldade de abastecimento alimentar. É esta uma referência a distintas temporalidades que anunciam diferentes noções de risco. Em alguma medida, cada relato parece também revelar certo apego, numa espécie de justificação do seu tempo.

$\mathrm{Na}$ esteira dessa discussão, reconhecem-se nesse diálogo geracional algumas das reflexões de Fischler (1995), para quem a modernidade alimentar e a tecnologia empregada a favor de um aporte variado de comidas à disposição dos comensais têm modificado, sobremaneira, os referenciais sobre os quais se funda 
o reconhecimento das características dos alimentos. Para esse autor, o comensal

moderno sofre da angústia cotidiana de incorporar o desconhecido. Trata-se de uma "crise biocultural da alimentação".

Essa significação negativa dos produtos industrializados, por parte, sobretudo, daquelas que são responsáveis pela alimentação no âmbito doméstico, foi também reconhecida por Arnaiz (1997) em estudo realizado na Espanha, e por outros estudiosos por ela referenciados, o que parece denotar um fenômeno que ultrapassa algumas fronteiras. Importa destacar que a autora faz referência também a determinados fatores considerados positivos do processo de expansão da industrialização de alimentos, coincidentes também com aqueles aludidos na narrativa acima.

Os aditivos e conservantes parecem povoar de modo mais notório a representação do risco associado ao comer. Arnaiz (1997) discute que a contradição no sistema alimentar provocado pela abundância e pela negação - temeridade a ela associada, em função dos riscos incorporados nos processos da agroindústria alimentar -, tem sido explicada por duas vias principais. Uma delas advoga que a negação traduz o mecanismo de racionalidade humana, uma resposta à abundância; a outra via compreende a negação como expressiva da insegurança provocada por processos anômicos indicativos do mundo de hoje. Por essa via, retorna-se a Fischler (1995) para pontuar o quanto as escolhas alimentares estão cada vez mais conflituosas, pois que arroladas numa crise de códigos e valores culturais que atuam nas decisões dos sujeitos.

\section{Alimentar, nutrir, comer... explorando sentidos}

$\mathrm{O}$ imbricamento das noções de risco parece oferecer distintos status às noções do que é comida ou não. Trata-se de uma ingestão que incorpora códigos advindos do conhecimento científico, desde aqueles identificados como "nutrição rica" e outros que adquirem outra conotação - porcaria -, desde que inoculados por signos da modernidade. Diz Luana:

$\mathrm{O}$ nosso corpo precisa da alimentação, porque se não se alimentar, não vive. Tanto que tem todo tipo de alimentação, porque tem alimentação que é mais rica e aquela que não é, aí tem que repor. [Rica em quê?] Rica na nutrição mesmo. Tem alimento que não traz benefício nenhum para saúde, só é porcaria, esses biscoitinhos, salgadinhos mesmo, miojo, então, nem se fala! O que é que tem nisso? Nada! Para mim, não alimenta nada. Mata fome, a vontade dos meninos, que adoram, mas não alimenta. Não pode comer só porque tá com fome não, sabe? Tem muita porcaria que não 
serve pra nada, hoje... antigamente, no tempo de minha mãe mesmo, a alimentação era mais saudável, acho que as pessoas comiam sem aquela preocupação, porque era tudo mais saudável, era tudo natural; hoje mais não, a gente tem que pensar o que vai comer, o que vai dar pra comer pras crianças, porque pode fazer mal.

Luana fornece na sua narrativa importantes signos que representam a modernidade tardia, tal como discutida por Giddens, e ainda as discussōes presentes nos trabalhos de Santos (2008), Azevedo (2008) e Sant'Anna (2003), conforme anunciado anteriormente. $\mathrm{O}$ tempo de hoje, diferente daquele vivido por sua mãe, apresenta uma pluralidade de alimentos que são "porcarias", que conferem risco à saúde e estão intimamente incorporados ao alimento, em referência ao predomínio do consumo de alimentos industrializados, considerados menos naturais, menos saudáveis. São questôes que alocam a necessidade de reflexão sobre o que comer, sendo que, nessa dimensão, é preciso repousar também o conhecimento daquilo que se come, do conteúdo que se ingere, tendo não somente a perspectiva de atender necessidades fisiológicas ou suprimir a fome, do ponto de vista social do fenômeno, mas devendo responder a uma dada racionalidade que tem a expectativa de não "fazer mal", de afastar os riscos à saúde.

Os três termos empregados na narrativa - alimentar, nutrir, comer - abrem algumas possibilidades analíticas, em que o comer solicita reflexão sobre o alimento que melhor vai nutrir o corpo. É a dimensão classificatória do alimento, sustentada por um dado conhecimento do que é mais nutritivo, apoiando a decisão do que se come no cotidiano. As três noções, de algum modo atreladas aos sentidos originários dos campos científicos que convencionalmente os articulam (CARVALHO; LUZ; PRADO, 2011), parecem imbricadas nessa narrativa, solicitando cumplicidade dos seus sentidos particulares, em função da presença do conhecimento científico mobilizando a decisão do que comer.

Outras narrativas possibilitam alguma aproximação sobre a imbricação desses termos - alimentar e comer -, construídas pelo que se reconhece de danoso e suspeito na alimentação moderna. Assim diz Tania:

Eu dou verdura porque eu sei que é bom, alimenta, aí tem que comer. Eu não gosto de verdura, não como, mas não faço isso na frente para não dar exemplo... É, principalmente pra criança que tá em crescimento, e aí aborrece mais pra comer, mas eles até que come sem problema... Nem tudo que é bom a gente pode dar, nem sempre tem uma fruta, tem uma variedade de coisa para dar, mas falta aí é condição mesmo... esse suco mesmo [mostra o suco envasado que o avô comprou para a criança], a gente 
sabe que não é bom hoje, que só tem açúcar, que é cheio de conservante, então já evito

de dar, mas ele adora mesmo é Toddynho, faço o Nescau em casa com leite em casa, mas pra ele não é a mesma coisa, ele só gosta mais do pronto que tem conservante, digo que não tem dinheiro, porque não tem mesmo, né? Teve uma vez que coloquei um pouquinho de maisena pra engrossar um pouco e ficar da grossura do Toddynho. Quem disse que enganou ele? Engana não. Criança é uma coisa, acho que só gosta dessas coisas que não faz bem pra saúde, que não alimenta direito, sei lá, acho que até colocam uma coisa pra viciar as crianças ... de vez em quando dou para fazer um agrado, mas não é sempre, não.

Os conhecimentos relativos aos aditivos e conservantes foram evocados com maior frequência nos grupos domésticos estudados, fazendo referência à classificação de alimentos que fazem bem ou não à saúde. Nessa narrativa, o significante que a agente traz à cena para a verdura é que ela é boa e, por consequência, alimenta; portanto, é imperativo comê-la, com uma acepção de obrigatoriedade mediada, sobretudo, por uma representação fisiológica da criança e ainda, talvez, pelo contraponto ao que seria uma comida tecnológica/ fabricada, uma vez que a verdura é mais natural, ainda que pesem sobre ela os agrotóxicos utilizados no sistema agroalimentar.

O comer aparece, nas duas narrativas precedentes, quer inoculado diretamente por conteúdos de natureza técnico-científicos, quer construído e margeado por informações dessa ordem. $\mathrm{O}$ alimento e o alimentar nessas narrativas são predicalizados ou referenciados no status da ordem do saudável, onde o bom, o nutritivo e o benéfico compóem o seu quadro de referência, através do qual as agentes expressam o que se deve comer. Dito de outro modo, o alimentar e o alimento vinculam-se ao organismo, ao corpo, à saúde, e esses símbolos se presentificam, se não na dimensão da experiência do comer, ao menos na estrutura da narrativa que a anuncia. Por outro lado, destaca-se que o conteúdo dos termos de alimentos bons/ruins, que alimentam/não alimentam, da alimentação rica/ pobre, não apresenta um quadro de estabilidade dos seus significados, podendo variar dentro do mesmo grupo social, ou, ainda, ao se considerar a referência na qual se assenta tal significação, se apoiada em perspectiva da saúde, da comodidade, da hospitalidade (ARNAIZ, 2010). Portanto, são significações cambiáveis e ajustáveis na dependência de grupos e referências socioculturais.

Os sentidos sobre alimentação e nutrição anunciados pelas informantes deste estudo estão margeados ou inoculados do significado de risco. Na gramática do campo social da alimentação e nutrição, os nutrientes e substâncias empregados na 
indústria alimentícia, a exemplo dos aditivos, parecem lograr maior notoriedade nesse teatro discursivo, representando o peso do sentido de risco nesse cenário.

D. Maria oferece outra narrativa sobre o sentido de comida quando, também em referência ao seu passado e ao tempo presente, nos informa o que seus netos não costumam gostar de comer. No seu tempo, conforme a matriarca, era tudo muito difícil, por um lado, ao se referir ao acesso ao alimento, mas, por outro, se dinheiro não havia para comprar comida no mercado ou na venda, recorriase ao vasto quintal ou ao mar logo à frente para garantir algo para comer. D. Maria apresenta um vasto repertório de folhas, de algumas “invenções" que fazia para garantir a comida para seus filhos, pois que o dia a dia do prato na mesa era muitas vezes dependente da sua capacidade criativa e inventiva para com os recursos de que dispunha no quintal ou no brejo para dar o de comer aos seus filhos. Diz D. Maria:

Antigamente, os pais diziam que tinha que comer, a gente comia, hoje não é mais assim. Quando não tinha o que comer, fazia língua de vaca e comia; não tinha leite, fazia mingau de farinha e tomava. Hoje, não é mais assim. Menino diz que não quer comer, que não vai fazer, que isso não é comida. E a gente sabe que isso que tem hoje aí é que não é comida, que tá tudo contaminado, envenenado. Comida era no meu tempo, mas eles não têm essa consciência, não. Só depois que a gente vai ver o prejuízo, adoecendo de um monte de coisa aí, e vai perguntar por que isso. Isso é aquilo que lhe dizia 'ói, que não é comida...' Antigamente, bebia água do brejo e não tinha nada, hoje a gente bebe da torneira, não pode, tem que filtrar senão adoece.

Dentre esses recursos, D. Maria faz referência à pinaúna - uma espécie de ouriço do mar - que sempre fazia como "escaldado" no almoço. D. Maria diz: "hoje não querem mais para almoço, fazem de brincadeira, pegam no mar e assam assim”. Além dos atributos de riscos presentes na narrativa de D. Maria e dos sentidos que se vinculam e se firmam aderentes a distintos contextos e tempos, pode-se reconhecer os conflitos e ruídos de sentido sobre comida nessa narrativa, mediada pelo risco associado à mesma, em função do alimento "contaminado", “envenenado", mas também decorrente do amplo repertório de gêneros alimentícios que se apresenta atualmente. Tal discussão apoia-se na "gramática da comida", tal como refletida por Montanari (2008), cujo léxico é constituído pelo repertório de produtos disponíveis ao consumo e, ainda, ao que se nomeia como comestível, seguindo uma racionalidade tanto econômica quanto cultural.

A categoria "comida" se diferencia entre os membros desse grupo doméstico. A narrativa de D. Maria é fruto de uma realidade social e histórica na qual ela vai 
buscar, no passado, recursos simbólicos, partilhando-os com os do presente para, assim, dar o sentido da comida. O risco da privação, símbolo maior e constante da sua cotidianidade no passado, solicitava a inventividade como sua premente estratégia de sobrevivência, ampliando, por certo, o léxico do seu sistema e gramática alimentar.

O símbolo da privação, que remete a circunstâncias passadas, permanece como sombra no imaginário de D. Maria, realidade com menos força e frequência no seu presente. No entanto, sua experiência e suas estratégias para enfrentamento da privação devem ser reatualizadas no diálogo com seus netos. Estes - como sujeitos de seu tempo - parecem apresentar outro repertório lexical, o qual se estrutura na base de um mercado vasto de produtos alimentícios.

Destaca-se que os netos reconhecem a pinaúna como da ordem do comestível, mas o seu consumo deve ser eletivo; quando não, um deslocamento se opera na categoria, revelando uma mudança de status. Reportando-se a considerações de Fischler (1995), um alimento pode mudar a posição que ocupa numa determinada estrutura alimentar, em função de mudanças de gostos e valores dos grupos sociais, condicionados, por sua vez, por transformações econômicas e sociais - o que parece ter acontecido com a pinaúna para as geraçôes mais novas.

A pinaúna representa para $\mathrm{D}$. Maria e a geração posterior o substituto de outros alimentos, quando da experiência de recursos mais escassos, não ferindo o seu leque de possibilidades alimentares, pois, segundo Montanari (2008), em situações de penúria é possível lançar mão de um conjunto de estratégias de sobrevivência. Contudo, estas tendem a não se desvincular da linguagem cultural que ordena a gramática da comida. As estratégias são variantes, modulações, inventividades, mas compõem o nicho cultural dos que delas se utilizam.

Nesse sentido, são vários os sentidos que se constroem na denominação do que se come, do que alimenta e nutre. Sentidos que se diferenciam no tempo, amparados pelas noções de risco vigentes a cada época.

\section{Consideraçôes finais}

A imagem tecnológica dos alimentos é insumo profícuo às narrativas sobre a alimentação cotidiana e sobre os modos de pensar as práticas de cuidado alimentar. Contudo, não se trata de uma composição monológica de cuidado, sustentado e redutível às noções de riscos que possam explicar os modos de ação 
que conferem sua forma. Antes, são recursos que as agentes acionam à reflexão e à justificativa de suas ações, posto que os alimentos inoculados dos riscos anunciados pelas agentes são também ingeridos em função de outras mediaçoes simbólicas nas quais se apoiam as práticas alimentares.

$\mathrm{O}$ reconhecimento de riscos e de nutrientes por parte das agentes revela que o risco ronda o comer em estado de ameaça e de colonização de futuro. $\mathrm{O}$ que aparentemente transparece é que a "ameaça das vitaminas" e os sentidos articulados por Cascudo (2004) para o apego aos cardápios tradicionais, ainda que não provoquem desajustes dos mesmos, sinalizam sentidos que cercam o comer de descontinuidades, expressivas das mudanças do mundo contemporâneo.

Deste modo, pode-se admitir que, relativo ao campo da alimentação e nutrição, o discurso do saudável - e sua imagem reversa, o risco - é estatuto que pode margear, inocular ou nele se enredar, produzindo práticas e sentidos mais ou menos fiéis, tanto na ordem da narrativa quanto da experiência, gerando toda ordem de incertezas a ele inerente. Destacamos que a utilização de três termos - margear, inocular e enredar - nesta discussão se deu de modo deliberado, na medida em que se entende que os caminhos de sentido a que os termos conduzem se distinguem, expressivos de fronteiras simbólicas e materiais múltiplas que se vinculam aos escapes, constrangimentos e contingentes do cotidiano.

Assim, em que pesem as reflexôes sobre as diferenças no âmbito do conhecimento e dos campos de saber em torno das categorias "comer", "alimentar" e "nutrir", no campo social essas práticas parecem cada vez mais tênues. Ainda que fronteiras mais notáveis entre os termos estejam no campo da prática, a fluidez com que elas se insinuam na dimensão narrativa suscita reflexões sobre práticas difusas do cotidiano, sobre as quais pesam esforços de delimitaçôes do campo científico, este sim talvez carecendo compreender os fenômenos para além das tradições e culturas dos seus campos disciplinares, como forma de apreender o horizonte e a pluralidade de práticas e sentidos.

Consideramos que comer/alimentar/nutrir, na contemporaneidade, são categorias sobrepostas ou fluidas no cotidiano dos sujeitos. Sobre a fluidez das práticas e sentidos em torno dessas categorias repousa também um caráter moralizador, que se situa não só nos tempos de hoje - de colonização de futuro -, mas estão na própria base histórica de todo modo de organização social.

Pode-se concluir que os sentidos construídos abrem-se em diálogo e correspondem a múltiplos campos de visão, coerentes com um tempo que 
alargou, a um só tempo, o contato com os riscos, mas as possibilidades de discursividades e de ação.

Os dados revelam ademais a necessidade de novos estudos que possam se debruçar sobre como estão organizadas categorias dietéticas alimentares em relação às informações sobre alimentação e nutrição, em diálogo com os saberes pré-existentes da tradição e da memória, em tempos de discursos hiperbólicos sobre o saudável e o risco. Nesse aspecto, concorda-se com Arnaiz (1997), para quem a cacofonia alimentar pode estar produzindo mais sentidos conflituosos que de fato uma apropriação de um saber nutricional ou científico por parte da população. ${ }^{1}$

\section{Referências}

ARNAIZ, M. G. La Transformación de la cultura alimentaria: câmbios y permanências em um contexto urbano (Barcelona, 1960-1990). Madrid: Centro de Publicaciones Del Ministerio de Educacion y Cultura, 1997. 318 p.

Paradojas de la alimentacion contemporânea. Barcelona: Içaria, 1996.

AZEVEDO, E. Reflexões sobre riscos e o papel da ciência na construção do conceito de alimentação saudável. Rev. Nutr., Campinas, v. 21, n. 6, p. 717-723, nov./dez. 2008.

AYRES, J.R.C.M. Desenvolvimento histórico-epistemológico da Epidemiologia e do conceito de risco. Cad. Saúde Pública [online]. 2011, v. 27, n. 7, p. 1301-1311.

CARVALHO, M.C.V.S.; LUZ, M.T.; PRADO, S.D. Comer, alimentar e nutrir: categorias analíticas instrumentais no campo da pesquisa científica. Ciênc. saúde colet., Rio de Janeiro, v. 16, n. 1, p. 155-163, jan. 2011. Disponível em: <http://www.scielo.br/scielo. php?script=sci_arttext\&pid=S1413-81232011000100019>. Acesso em: 01 fev. 2011.

CASTIEL, L.D. ; GUILAM, M.C.R.; FERREIRA, M.S. Correndo o risco. Uma Introdução aos riscos em saúde. 1. ed. Rio de Janeiro: Fiocruz, 2010. v. 1. 134 p.

CZERESNIA, D. O conceito de saúde e a diferença entre prevenção e promoção. In: . (Org.). Promoção da saúde: conceitos, reflexões, tendências. Rio de Janeiro: Fiocruz, 2003. p. 39-53.

FISCHLER, C. Gastro-nomía y Gastro-anomía. Sabiduria Del cuerpo e criys biocultural de la alimentación contemporânea. In: CONTRERAS, J. (Org.). Alimentácion y Cultura: necessidades, gustos e costumes. Barcelona: Universitat de Barcelona, 1995. 1995. p. 357-378. GIDDENS, A. Modernidade e identidade.. Rio de Janeiro: Jorge Zahar, 2002. 233p.

. Mundo em descontrole: o que a globalização está fazendo de nós. 6. ed. Rio de Janeiro: Record, 2007. 109p. 
LUPTON, D.; SIMON, C. A healthy lifestyle might be the death of you: discourses on diet, cholesterol control and heart disease in the press and among the lay public. Sociology of Health e Illness., v. 17, n. 4. 1995, p.477-494

LUZ, M. Novos saberes e práticas em saúde coletiva: estudo sobre racionalidades médicas e atividades corporais. São Paulo: Hucitec, 2003. p. 87-134.

MENÉNDEZ, E.L. Grupo doméstico y proceso salud/enfermedad/atención: del 'teoricismo'al movimiento continuo. Cuadernos Médico Sociales, Rosario, n. 59, p. 3-18, 1992.

MONTANARI, M. Comida como cultura. São Paulo: Senac São Paulo, 2008. 207p.

ORY, P. O corpo ordinário. In: CORBIN, A.; COURTINE, J-J.; VIGARELLO, G. (Org.). História do Corpo. Petrópolis: Vozes, 2008. p. 155-195 (As mutações do olhar: o século XX, v.30).

POULAIN, J.P. Sociologias da slimentação: os comedores e o espaço social alimentar. Florianópolis: EdUFSC, 2004. 311p. (Série Nutrição).

RANGEL, M.L. Comunicação no controle de risco à saúde e segurança na sociedade contemporânea: uma abordagem interdisciplinar. Ciênc. saúde coletiva. Rio de Janeiro, v.12, . 5, p. 1.375-1.385, out 2007. Disponível em: http://www.scielo.br/scielo.php?script=sci_ arttext \&pid $=$ S1413-81232007000500035\&lng=en. Acesso em: 10 maio 2012.

SANT'ANNA, D.B. Bom para os olhos, bom para o estômago: o espetáculo contemporâneo da alimentação. Pro-Posições, Campinas, v. 14, n. 2, p. 42-52, maio-ago. 2003.

SANTOS, L.A.S. O corpo, o comer e a comida. Um estudo sobre as práticas corporais e alimentares cotidianas a partir da cidade de Salvador. Salvador: EDUFBA, 2008. 330p.

SFEZ, L. A saúde perfeita: crítica de uma nova utopia. São Paulo: Loyola, 1996. 395p.

VAZ, P. et al. O fato de risco na mídia. Interface Comunicação, Saúde, Educação. Botucatu, v. 11, n. 21, p. 145-63, jan/abr 2007

VILLAGELIM, A.S.B. et al. A vida não pode ser feita só de sonhos: reflexões sobre publicidade e alimentação saudável. Ciênc. saúde coletiva. Rio de Janeiro, v. 17, n. 3, p. 681-686, mar 2012. Disponível em: http://www.scielo.br/scielo.php?script=sci_arttext\&pid=S141381232012000300014\&lng=en. Acesso em: 10 maio 2012.

\section{Nota}

${ }^{1}$ M.D. Soares trabalhou na concepção, coleta e análise de dados e redação do artigo. L.A.B. Trad contribui na concepção, análise e revisão crítica do artigo. 
The senses of risks attributed to food among household caregivers

This study aimed to understand the meanings given to speech in the social field about food and nutrition by children's household caregivers. It was an ethnographic study in an urban context with low level population. In the city of Salvador, Bahia, Brazil, along a year (2010), observation and semi-structured interviews with household caregivers were conducted, according to the meaning interpretation method. The meanings about food and nutrition that emerged were related to risks in a perspective of scientific speech; food image was strongly associated with technological process present in daily feeding. However, it was not a standard in the social groups observed, considering the reference on which rests that meaning.

> Key words: risk-taking; alimentation; dietary practices. 